\title{
$A^{=m}$
}

\section{EDUCAÇÃO PARA OS DIREITOS HUMANOS: LIMITES E POSSIBILIDADES}

Simone Cristina Nazareth ${ }^{1}$; Daiana Cristina do Nascimento ${ }^{2}$; Marta Regina Farinelli ${ }^{3}$

\begin{abstract}
RESUMO
O presente artigo visa uma reflexão acerca das dificuldades da materialização da educação pautada nos direitos humanos, bem como os seus benefícios. Ressalta-se o - PET Programa de Educação Tutorial Conexões de Saberes, como uma das estratégias para a disseminação das informações sobre os direitos previstos nas legislações vigentes, uma vez que a maioria dos indivíduos desconhece os mesmos, o que deveria ser o escopo de todos os cidadãos.
\end{abstract}

Palavras-Chave: Direitos Humanos. Educação. PET - Programa de Educação Tutorial.

\section{ABSTRACT}

This article is a reflection on the difficulties of materialization of education guided human rights, as well as its benefits. It is noteworthy the - PET Education Program Tutorial Knowledge Connections, as a strategy to disseminate information on the rights provided for in existing laws, since most people know the same, what should be the scope of all citizens.

Keywords: Human Rights. Education. PET - Education Tutorial Program.

\section{INTRODUÇÃO}

A sociedade contemporânea, permeada pelo sistema econômico capitalista, configurase pelas suas relações contraditórias, refletindo na dualidade de classes e nas diversas facetas das expressões da questão social. Esse cenário, voltado para o consumo e o lucro desenfreado, estabelecem diversos condicionantes no cotidiano dos sujeitos sociais.

Nesse contexto de disparidades, encontra-se inserida a Declaração Universal dos Direitos Humanos, adotada e proclamada pela resolução 217 A (III) da Assembleia Geral das Nações Unidas em 10 de dezembro de 1948, tendo como propósito atingir todos os povos e nações, sem qualquer discriminação de origem, raça, cor, sexo, língua, religião, opinião

\footnotetext{
${ }^{1}$ Universidade Federal do Triangulo Mineiro. Email: cris.lara3@gmail.com

${ }^{2}$ Universidade Federal do Triangulo Mineiro. Email: daiananascimentto@hotmail.com

${ }^{3}$ Universidade Federal do Triangulo Mineiro. Email: martafarinelli@gmail.com
} 
política ou de qualquer outra natureza, respeitando-os nas suas singularidades e reafirmando o compromisso com a igualdade e liberdade de todos em face dos direitos.

Nesta perspectiva, com a promulgação da Constituição Federal 1988 houve um avanço na legislação brasileira, especialmente na área da extensão dos direitos sociais e políticos aos cidadãos, reafirmando o reconhecimento dos direitos humanos em seu Art. 3, declarando como objetivos fundamentais da República Federativa do Brasil, a construção de uma sociedade livre, justa e solidária, a erradicação da pobreza e da marginalização, a redução das desigualdades sociais e regionais e a promoção do bem de todos, sem preconceitos de origem, raça, sexo, cor, idade e quaisquer outras formas de discriminação. (CONSTITUIÇÃO FEDERAL, 1988, p.13)

Contudo, segundo Benevides (1998), a democracia brasileira foi baseada num modelo de Estado de concepção neoliberal ao qual pode se destacar a hegemonia dos direitos políticos sobre os direitos sociais. Diante disso, verifica-se frequentes violações dos direitos mais rudimentares com um acréscimo cada vez maior de sujeitos excluídos do processo de desenvolvimento, destituídos das condições de dignidade humana.

Estudos demonstram que as transformações societárias, impulsionadas pelo surgimento do capitalismo e aceleradas com o neoliberalismo, estão culminando em uma educação mercadológica, voltada para os interesses econômicos da minoria dominante e com isso, negligenciando o verdadeiro papel da educação como instrumento de participação política e emancipação humana.

Nesta direção, faz-se necessário a fomentação de estratégias propositivas visando à materialização da educação em direitos humanos, visto que a mesma oferece subsídios para o fortalecimento de uma sociedade mais justa e igualitária, em que os sujeitos sociais passam a ter conhecimento sobre os seus direitos, tornando os assim, cidadãos concretos protagonistas ativos nessa sociedade ambígua e desigual.

Assim sendo, como afirma Montoro (1999), não basta ensinar direitos humanos, é preciso lutar pela sua efetividade, e, acima de tudo, trabalhar pela criação de uma cultura prática desses direitos. Dessa forma, o PET - Serviço Social - Conexões de Saberes da Universidade Federal do Triângulo Mineiro (UFTM), localizada em Uberaba - MG realiza o projeto intitulado de "Educação para os direitos humanos: já" com intuito de mobilizar os alunos oriundos de escolas públicas a refletir acerca dos direitos humanos e sociais, com foco aos direitos: à vida, à escola, à moradia, ao meio ambiente, à saúde e à participação; que por vezes são violados. 


\section{EDUCAÇÃO PARA OS DIREITOS HUMANOS}

As declarações de direitos humanos do mundo contemporâneo apareceram a partir de correntes filosóficas sobre influência do racionalismo e jusnaturalismo. Este momento caracterizou-se como o apogeu do Iluminismo ou Ilustração. Amparava-se, essencialmente, que o homem, teria direitos naturais. Entretanto, de acordo com a história, o conceito de direito natural não surge com o jusnaturalismo moderno; remonta, antes, ao pensamento cristão e clássico, aos grandes moralistas, poetas e escritores da Antigüidade.

A inovação trazida pelo Iluminismo foi a tradução do direito natural em lei escrita, por meio das declarações de direito, assim como a Declaração Americana de Direitos, de 1776, e a Declaração Francesa dos Direitos do Homem e do Cidadão, de 1789. (BOBBIO, 1992)

Como afirma Deleuze (1992) os direitos humanos desde suas origens têm servido para conduzir aos sujeitos socialmente inferiores a fantasia de participação, de que as classes dominantes preocupavam-se com o bem estar, afirmando assim que o humanismo no capitalismo é uma realidade e com isso confirma-se o artigo primeiro da Declaração de 1948: "todos os homens nascem livres e iguais em dignidade e direitos".

Contudo, os segmentos pauperizados da sociedade sempre estiveram fora desses direitos à vida e à dignidade, entendidos como "marginais". A esses, efetivamente, os direitos humanos sempre foram, e permanecem sendo negados, já que tais segmentos foram determinados para serem vistos como "sub-humanas", não se vendo como seres humanos.

Assim, direitos proclamados pelas diversas revoluções burguesas, contidos nas mais variantes declarações, possuem um claro conteúdo de classe. Os excluídos dos séculos XIX e $\mathrm{XX}$ nunca fizeram parte desse grupo privilegiado que teve seus direitos respeitados e garantidos, como afirma Marilena Chauí ( 1989,p.20)

A prática de declarar direitos significa, em primeiro lugar, que não é um fato
óbvio para todos os homens que eles são portadores de direitos e, por outro
lado, significa que não é um fato óbvio que tais direitos devam ser
reconhecidos por todos. A declaração de direitos inscreve os direitos no
social e no político, afirma sua origem social e política e se apresenta como
objeto que pede o reconhecimento de todos, exigindo o consentimento social
e político

A luta pelos direitos humanos no Brasil surgiu com mais eficácia nos movimentos contra a ditadura militar. Especialmente no começo dos novos movimentos sociais que se concretizaram também no período repressivo, na metade dos anos 1970. Decorreram das 
práticas que começaram a rechaçar os movimentos tradicionalmente estabelecidos e que politizaram o dia a dia nos lugares de trabalho e moradia, idealizando inovações políticas. Vieram quando os "novos sujeitos políticos" que, no cotidiano, batalhavam por melhores condições de vida, trabalho, salário, moradia, alimentação, educação, saúde e pela democracia na sociedade.

A realidade brasileira nesse período histórico foi marcada pela não viabilização dos direitos humanos como conteúdo e como conhecimento prático, dado o processo de cerceamento da participação social, a prisão, o exílio e a morte de centenas de ativistas que se contrapunham à ditadura militar.

Enquanto isso, na década de 1980, assistimos a uma competente campanha, principalmente via meios de comunicação, que discretamente fala sobre o acréscimo no nível da criminalidade relacionando-o ao término da ditadura militar. Campanhas acobertavam o auto armamento da sociedade, a defesa dos linchamentos, o policiamento ostensivo e fardado nas ruas.

A violência vira-se assunto nacional favorito pelos meios de comunicação e pelos políticos, e as elites fazem da criminalidade sua principal trincheira de luta, em particular, nos estados do Rio de Janeiro e de São Paulo.

Posteriormente, as votações para governadores, em 1983, ganham nesses dois estados, partidos de oposição que ressaltam os discursos sobre os direitos humanos: é quando mais intensamente são veiculados pelos diferentes tipos de mídia os temas sobre o crescente aumento da violência nesses dois espaços.

O término dessa década foi marcado por um perturbado momento histórico: o fechamento das opções verdadeiras à sociedade de mercado no mundo e a consciência crescente de que, no subterrâneo da eloquência dos direitos, desejava principalmente o neoliberalismo. Significou um período de proclamação do fim das ilusões. Porém, a sociedade brasileira, habitava em tempos de institucionalização de suas lutas, com a nova Constituição. Com eles, a criação da constituição de bases sociais mais sólidas para a concretização dos direitos humanos.

A própria força que levou a Constituição a ser regularizada pelos direitos humanos, ponderadas as situações, viu-se devastada por um governo que destituía contra ela. As forças populares lutaram, mesmo sem obter a abertura de novo período político e, especialmente, a prática de mudanças econômicas e sociais estruturantes. 
Nesse cenário caracterizado não só por medidas neoliberais, mas ainda por massacres, balas perdidas, linchamentos, homicídios de crianças e adolescentes, de homossexuais, de pessoas carentes com suspeitas de crimes, de trabalhadores e líderes sindicais rurais que o governo federal divulga, em 07 de setembro de 1995, (dia da Independência do Brasil), seu intuito de realizar um Plano Nacional de Direitos Humanos. Aproveitando-se massivamente dos meios de comunicação, como resposta às forças internacionais pelas metódicas violações de direitos humanos, o governo federal apregoa que "direitos humanos é o novo nome da liberdade e da democracia” (Presidência da República, 1995).

Posteriormente ao anúncio do Plano, designou-se a Secretaria Nacional de Direitos Humanos, órgão responsável por sua implementação e coordenação. No entanto, este órgão não computa qualquer participação da sociedade civil, não dispõe de recursos financeiros próprios ou suficientes para execução de suas atribuições e, assim, até atualmente, não fiscalizou, monitorou e pôs em prática o Plano. Não se obteve então em um Programa, estando, ainda um documento com fins simplesmente declaratórios.

Ainda na década de 1990, ganha maior importância a preocupação e o interesse com a solicitação de uma educação norteada para os direitos humanos, em 1995, da década da educação em direitos humanos, terminada, em 2004, com a aceitação, no ano seguinte, do Programa Mundial de Educação em Direitos Humanos (PMEDH) e seu Plano de Ação. Esse debate repercute no Brasil no mesmo período, sobretudo na esfera das organizações da sociedade civil e, em 2003, ganha maior legitimidade, com a invenção do Comitê Nacional de Educação em Direitos Humanos e abertura da preparação de uma primeira versão do Plano Nacional de Educação em Direitos Humanos (PNEDH) no país, enfim aprovado em 2006.

Segundo essa definição, a educação em direitos humanos pode ser considerada como uma educação permanente e global, que não cogita apenas a dimensão da razão e da aprendizagem cognitiva, mas abrange também aspectos afetivos e valorativos que carecem serem sentidos, vivenciados. É necessário conhecer os direitos à liberdade, à igualdade, à justiça e à dignidade para que se consiga difundi-los (BENEVIDE, 2001, p. 47).

Nesse sentido, a Educação em direitos humanos compreende o desenvolvimento social e emocional de todos os envolvidos no procedimento de ensino-aprendizagem, objetivando desenvolver uma cultura em direitos humanos, em que estes são exercitados e vividos nas escolas e demais instituições públicas, em relação com a comunidade local.

A defesa, a proteção e a promoção da educação em direitos humanos, como práticas a serem conquistadas pelas várias esferas da sociedade, determinam que as escolas e 
instituições adotem um compromisso constante com o fortalecimento de uma cultura de direitos humanos no país, materializando o Estado Democrático de direito e cooperando para o avanço da qualidade de vida da sociedade brasileira.

Contudo, numa época em que especialistas de ensino se preocupam em como adaptar a educação às novas tecnologias, que avançam cada vez mais rápido, o Brasil ainda tem pelo menos 16 milhões de analfabetos, o que representa 13,6\% das pessoas com 15 anos ou mais. Além disso, de cada cem alunos que entram na escola, 41 não terminam a $8^{a}$ série. (FOLHA DE SÃO PAULO, 2013, online)

Entre as causas do problema estão a falta de qualidade das escolas, aliada a professores mal preparados e mal remunerados, além do tempo reduzido em que o aluno fica na escola -cerca de 4,3 horas por dia, segundo o presidente do Inep (Instituto Nacional de Estudos e Pesquisas Educacionais), Otaviano Helene. Também contribui o gasto que a família tem para manter o filho estudando, o que acaba levando à evasão. (FOLHA DE SÃO PAULO, 2013, online)

A educação permanece vertical, o professor ainda é um ser superior que ensina a ignorantes. Isto forma uma consciência bancária. $\mathrm{O}$ educando recebe passivamente os conhecimentos, tornando-se um depósito do educador. Educa-se para arquivar o que se deposita. Mas o curioso é que o arquivado é o próprio homem, que perde assim seu poder de criar, se faz menos homem, é uma peça. O destino do homem deve ser criar e transformar o mundo, sendo sujeito de sua ação. (FREIRE, 2001, p.38)

Respaldada pelo artigo Art. 207 da Constituição Federal, que traz em seu bojo que

[...] as universidades gozam de autonomia didático-científica, administrativa e de gestão financeira e patrimonial, e obedecerão ao princípio de indissociabilidade entre ensino, pesquisa e extensão, a UFTM, tem cumprido seu papel no sentido de "atuar na geração, difusão, promoção de conhecimentos e na formação de profissionais conscientes e comprometidos com o desenvolvimento sócioeconômico, cultural e tecnológico. (CONSTITUIÇÃO FEDERAL, 1988,p.134)

Assim, dentre os vários programas e projetos oferecidos destaca-se o PET - Serviço Social (Conexões de Saberes) da Universidade Federal do Triângulo Mineiro que iniciou suas atividades em Dezembro de 2010, (edital 025/2010/ProExt) e possui como objetivo geral:

[...] contribuir para que o acadêmico realize uma leitura críticoreflexiva e propositiva acerca das transformações societárias, análise 
sobre as perspectivas de enfrentamento das expressões da questão social e desenvolva habilidades e competências para a construção de estratégias para a efetivação dos direitos humanos no âmbito acadêmico com impacto na sociedade local e regional. (PROJETO DO PET- SERVIÇO SOCIAL, 2011, p. 03)

Para uma abordagem das atividades realizadas faz-se necessário explanar sobre a criação do PET (Programa de Educação Tutorial) Conexões de Saberes instituído através da portaria MEC $\mathrm{n}^{\circ} 1$, de 17 de maio de 2006, com intuito de desenvolver ações que propiciem uma troca de saberes, experiências e demandas entre a comunidade e a universidade. Os discentes inseridos nesse programa são oriundos de camadas populares, fomentam projetos e trabalhos pautados na indissociabilidade entre pesquisa, ensino e extensão, com a possibilidade dos mesmos dedicar integralmente aos estudos, visto que o MEC - Ministério da Educação oferece apoio financeiro e metodológico. (MEC, 2013, on line)

Destarte, o PET - Serviço Social - Conexões de Saberes da Universidade Federal do Triângulo Mineiro (UFTM), localizada em Uberaba - MG realiza o projeto intitulado de "Educação para os direitos humanos: já" com intuito de mobilizar os alunos oriundos de escolas públicas a refletir acerca dos direitos humanos e sociais, com foco aos direitos: à vida, à escola, à moradia, ao meio ambiente, à saúde e à participação; que por vezes são violados.

O projeto de extensão "Educação para os direitos humanos: já" partiu da necessidade de disseminação dos direitos humanos e sociais, uma vez que os sujeitos em sua maioria desconhecem os espaços que lhes são conferidos e os direitos que deveriam ser efetivados, não tendo assim subsídios para o exercício pleno da cidadania.

Para tanto, o grupo de extensionistas realizaram um estudo bibliográfico sobre as políticas de educação, direitos sociais, humanos, concepção de educação, comunicação, função pedagógica do Assistente Social, entre outros.

Nesse sentido, o presente projeto se encontra respaldado pela teoria e o método dialógico de Paulo Freire, visto que o antidiálogo é a causa para a invasão cultural, da domestificação dos seres e a negação da autonomia dos mesmos em participar, tomando-lhes o poder de decisão. O antidiálogo não educa, ao contrário: "em vez de libertar o homem, escravisa-o, redu-lo a coisa, manipula-o, não permitindo que ele se afirme como pessoa, que atue como sujeito, que seja autor da história e se realize nesta ação fazendo-se verdadeiramente homem." (FREIRE, 1983, p.07).

Com o uso de tecnologias, dinâmicas de grupo, dramatização e exposição dialogada o Grupo PET começou suas atividades em duas escolas municipais de ensino fundamental e 
duas casas de proteção, localizadas em Uberaba- Minas Gerais, sendo evolvidos cerca de cento e cinquenta sujeitos. No conteúdo norteador, cada oficina abordou as diversas vertentes dos seguintes direitos: Direito à Vida, Saúde como Direito, Direito ao Meio Ambiente Saudável, Direito à Moradia, Direito à Escola e Direito à Participação.

A cada encontro realizado ficou perceptível, que os alunos das redes municipais tinham muitas indagações, ou seja, os mesmos não possuíam conhecimento acerca dos seus direitos, sobre os espaços públicos que lhes são conferidos, no entanto, as oficinas possibilitaram a eles uma apropriação dessas informações, antes desconhecidas. Enquanto isso, os adolescentes das Casas de proteção possuíam conhecimento acerca da temática abordada, pois os conteúdos apresentados se encontram presentes no cotidiano da instituição a qual eles se encontram inseridos.

Projetos como estes, reafirmam o compromisso com a educação de qualidade, que rompa com os ciclos de alienação e manipulação, gerados pela educação mercadológica, fazendo com que os estudantes se enxerguem como cidadãos críticos-reflexivos, conscientes dos seus direitos e responsabilidades, podendo exercer sua cidadania contribuindo para sua emancipação.

Por tudo isso, a democratização da escola pública - ou melhor, a sua refundação enquanto uma escola efetivamente popular - é uma tarefadesafio ainda em aberto para os educadores. O projeto aparentemente irrealizável - é construir uma educação pública que seja, ao mesmo tempo, democrática (extensiva a todos, indistintamente) e portadora de uma determinada qualidade, que seja socialmente referenciada e distante da lógica excludente. Uma escola que consiga inserir as novas gerações num mundo inteiramente transformado e distante daquele que originou a sua universalização. (BARROSO, 2005, p.11)

Em síntese, os conteúdos abordados nas oficinas realizadas, vão ao encontro dos princípios fundamentais do código de ética profissional dos assistentes sociais aprovado em 15 de março de 1993 com as alterações introduzidas pelas resoluções CFESS n. ${ }^{\text {o } 290 / 94 ~ e ~}$ 293/94, que traz como um dos princípios norteadores da profissão "a busca da eqüidade e justiça social, que assegure universalidade de acesso aos bens e serviços relativos aos programas e políticas sociais, bem como sua gestão democrática”. Dessa forma, o PET Serviço Social - Conexões de Saberes e a categoria profissional, estão na luta pela efetivação de uma educação pública de qualidade, pautada na emancipação humana, pois acreditamos que através dela avançaremos para uma transformação social. 


\section{CONSIDERAÇÕES FINAIS}

Diante das reflexões elucidadas no presente exposto, constata-se que os direitos humanos foram criados como resposta às violações desenvolvidas na sociedade voltada para o lucro e consumo desenfreado, posto que o Estado não atende todas as demandas das comunidades, principalmente as dos segmentos populares, transferindo assim, sua responsabilidade para as Organizações não governamentais e para as instituições filantrópicas.

Para tanto, segundo Michael Ignatieff, a linguagem dos direitos humanos existe para nos lembrar de que alguns abusos são realmente intoleráveis e que algumas desculpas para tais abusos são realmente insuportáveis. Dessa forma, a implantação de uma educação pautada nos direitos humanos, é um desafio a ser conquistado na contemporaneidade, ao passo que vivemos em uma sociedade culturalmente voltada para os interesses do capital, em que a ótica neoliberal restringe a educação como uma forma de qualificação de mão de obra.

Nesse cenário, faz-se necessário uma responsabilidade compartilhada com todos os setores com intuito de perpassarmos a lógica da educação mercadológica, uma vez que devem ser fomentados mais projetos como o do PET - Serviço Social Conexões de saberes, que reafirma a disseminação e a efetivação dos direitos resguardados nas legislações, diminuindo assim, a discrepância do que se tem no papel e o que realmente se materializa.

\section{REFERÊNCIAS}

BARROSO, Geraldo. A construção de uma escola pública "popular”: registro de um projeto inconcluso. In: V Colóquio Internacional Paulo Freire - Recife, 19 a 22-setembro 2005.

BENEVIDES, Maria Victoria. Democracia de iguais, mas diferentes. In: BORBA, A., FARIA, N., GODINHO, T. (org.) Mulher e política: gênero e feminismo no Partido dos Trabalhadores. São Paulo: Ed. Fund. Perseu Abramo, 1998.

BENEVIDES, Maria Vitória. Educação em Direitos Humanos: de que se trata? Convenit Internacional (USP), v. 6, p. 46-50, 2001. 
BRASIL. Constituição (1988). Constituição da República Federativa do Brasil. Brasília, DF, Senado, 1998 .

CARBONARI, Paulo César. A construção dos Direitos Humanos:: Uma breve leitura histórica de elementos para a compreensão da institucionalização dos direitos humanos no Brasil. Rev. Eletrônica Portas, São Paulo, n. 0, p.05-14, jun. 2007.

CARVALHO, José Sérgio. (org.) Direitos humanos e educação: outras palavras, outras práticas. São Paulo: Cortez, 2005.

CONSTANTINO, Luciana. Má qualidade da educação afeta futuro dos brasileiros. Folha de São Paulo, Brasília, 17 de Mar. 2003. Disponível em:http://www1.folha.uol.com.br/folha/educacao/ult305u12632.shtml. Acesso em: 28/03/2013.

CHAUI, M. S. Direitos humanos e medo. In: Fester, A.C.R.. (Org.). Direitos humanos e .... 1ed.São Paulo: Brasiliense, 1989, v. , p. 15-36.

FREIRE, Paulo. Educação e mudança. 24.ed. São Paulo:Paz e Terra, 2001.

REIRE, Paulo. Extensão ou comunicação? 12. ed. Editora Paz e Terra, 1972.

MOEHLECKE, Sabrina. Direitos Humanos e Educação. Salto Para O Futuro, Brasília, n. 1982-0283, p.01-68, mar./abr. 2008 apud Norberto Bobbio, 1192.

MONTORO, André Franco. "Cultura dos Direitos Humanos". In: Direitos humanos: legislação e jurisprudência (Série Estudos, n. 12), Volume I. São Paulo: Centro de Estudos da Procuradoria Geral do Estado, 1999.

ORGANIZAÇÃO DAS NAÇÕES UNIDAS. Declaração Universal dos Direitos Humanos. ONU, $1948 . \quad$ Disponível em: http://portal.mj.gov.br/sedh/ct/legis_intern/ddh_bib_inter_universal.htm. Acesso em:23/03/2013. 
Palestra realizada no Seminário "Pesquisa e Direitos Humanos", promovido pelo CRP - 06 e Programa de Pós-graduação em Psicologia da FFCLRP, em Ribeirão Preto, em agosto de 1999 apud DELEUZE. G. Conversações. Rio de Janeiro, Ed. 34, 1992.

SIMÕES, Carlos. Curso de direito do serviço social. 5. ed. São Paulo: Cortez, 2011. (Biblioteca básica de serviço social; v.3) 583 p.

SUZA, Herbert De. Como se faz análise de conjuntura. 22. ed. Rio de Janeiro: Vozes, 2002. . EDITAL 025/2010/ProExt de 26 de novembro de 2010. Disponível em:

,http://www.uftm.edu.br/upload/noticias/Edital_Conexoes_Saberes_PET_SS.pdf.. Acesso em: 23. mar.2013.

http://www.mec.gov.br/

RECEBIDO EM: 20/09/2013.

APROVADO EM: 25/09/2015. 